\title{
ZBLE: Zone based Leader Selection Energy Constrained AOMDV Routing Protocol
}

\author{
${ }^{\mathrm{a}}$ Rani Sahu, ${ }^{\mathrm{b}}$ Sanjay Sharma, ${ }^{\mathrm{c}}$ M.A. Rizvi \\ ${ }^{a}$ Research Scholar, Department of Computer Applications, Maulana Azad National Institute of Technology \\ Bhopal, India \\ ${ }^{b}$ Professor, Department of Computer Applications, Maulana Azad National Institute of Technology Bhopal, \\ India \\ ${ }^{c}$ HOD, Department of Computer Technology and Application NITTTR Bhopal (M.P.) India
}

Received: 08 March 2019; Accepted: 22 April 2019; Published: 08 September 2019

\begin{abstract}
In today's life, wireless networks (WNs) are being used very fast in every area. Wireless networks have been used in various applications, but finding some of its weaknesses, such as mobility, diversity, lack of resources and so on, finding an optimum route is very complex and problematic. By reducing the energy consumption on each node, the quality of the network can be ensured. Need to increase the battery life of the node to increase the network lifecycle. Therefore, reducing the energy consumption can extend the battery life of the node. To find and maintain routes between nodes, multi-path routing is a fundamental research issue for such networks. This paper discusses the zone-based routing protocol, which uses the energy, distance and power of the node to maintain high circulation and accelerate the path search process and maintain high search. The Zone-based Leader Selection Routing Protocol (ZBLE) is one of the new protocols, which is a modified form of the famous Ad Hoc on Demand Distance Vector Routing Protocol (AOMDV). Zone Leader Node and Zone Members are selected using the value of energy, position and power of the node. The performance of the proposed communication protocol is evaluated with other existing protocols such as AODV and AOMDV. The simulation result is that when it receives the best path for data communication with proper energy conservation. Network simulator version 2.35 is used for simulation purpose. To support our ideas, we used the 5 quality of service parameters such as packet distribution ratio, energy consumption, network lifetime, and throughput.
\end{abstract}

Index Terms: Energy efficient protocol, Mobile Ad-hoc network, multipath routing, and Zone Based function

(C) 2019 Published by MECS Publisher. Selection and/or peer review under responsibility of the Research Association of Modern Education and Computer Science

\footnotetext{
* Corresponding author. Tel.:

E-mail address: rani.princy28@gmail.com,ssharma66@rediffmail.com, marizvi@hotmail.com
} 


\section{Introduction}

Routing protocols can be classified into three parts: reactive, active and hybrid in the MANETs [40]. In the reactive routing, the paths are determined on the request and the nodes have no prior knowledge of the destination nodes. In active routing, evaluates the paths for each node in the network and each node continuously checks. In hybrid routing, uses zones and cluster-based routing. The purpose of this routing is to reduce the vulnerabilities of the active approach and exploit the powers.

The use of communication technologies between wireless devices and these devices has advanced in recent years. In addition, it is also expected that the use of mobile wireless computing and applications will be increasingly widespread. Most future developments are likely to have such a topology, which is multi-hop, dynamic, random, and sometimes varies rapidly.

Ad Hoc Networks are made of mobile nodes that communicate on wireless links without central control. Such networks are important in the development of wireless networks. Due to multi-hop nature, lack of fixed infrastructure, and self-route, and many problems are inherited directly from the ad hoc network. Such as bandwidth optimization, transmission quality enhancement and power control [1]. The Internet Engineering Task Force has made several proposals on various methods and protocols to prevent these issues. And even many standardization efforts are being made in academic and industrial undertakings [2]. In MANETs, mobile nodes have an impact on the network due to the limited battery. Due to the limited battery, network connectivity and its lifetime decreases. A routing protocol based on energy and power [3] is needed to extend the life of the network and strengthen network connectivity. There is a protocol to increase the network life, which selects such nodes to carry forward the data in which their batteries have high energy levels. And such protocol nodes reduce energy consumption. Using such protocols in MANET [4], different route cost and path selection algorithms have been examined, which aims at improving energy efficiency. During the past years, many multi-path routing protocols have been developed, designed to increase the life span of a path and increase network performance. [5]

The Multipath Path Protocol is one of these incidents, which enables the source node to choose the best route from multiple routes during the single path search process. The path of multipath routing will reduce the number of search processes. If someone fails, another good route can be chosen with the help of the backup route. Use of multipath technology will reduce end-to-end delay, energy consumption, and network life will increase. [6] There are many problems with multipath routing protocols. It is not necessary that the source will always be available optimal or shortest way. These problems become more complex with a large number of mobile nodes. In this case, most energy is being consumed at the time of testing the lowest routes. After this, more energy is lost on data transfer. Because the power source of mobile nodes is limited, so the energy consumption should be controlled by these nodes to increase the life of the network [7]. It offers paper zonebased energy efficient multipath routing protocol called Zone Based Leader Selection Energy Constrained AOMDV Routing Protocol (ZBLE). This protocol selects all the zones on the basis of energy level and power to forward the data using the Zone Creation and Leader Node Selection Algorithms, from which the best path for data forwarding can be chosen. Based on some of our current simulation results, ZBLE performances have been compared against other standard routing protocols like AODV and AOMDV. Both protocols are the most popular protocols used in mobile ad hoc networks. These protocols have been standardized by the Internet Engineering Task Force (IETF). These protocols are well tested for real-world applications. Because of these reasons, they have been selected to compare their performance against ZBLE.

In this paper, we offer a modern routing approach that can consider zone-based techniques for energy conservation and best path analysis. Not only considering energy, but by designating a multipath routing approach by fulfilling the routing process in an efficient way, the main challenge is to do this. In order to fulfill this challenge, this letter is organized as the following. Section I has presented ZBLE protocol in detail.

The proposed protocol ZBLE and its functionality have been described in Section II. Methodology and Proposed algorithm for ZBLE is introduced in Section III and Section IV. Section V presents and the simulation environment and simulation results. Finally, section VI concludes on research. 


\section{Zone Based Leader Selection Energy Constrained Aomdv Routing Protocol (Zble)}

Our protocol is based on zone-based technology and relies on network decomposition in embedded areas. Although many routing protocols have been designed for Ad hoc Networks, the importance of implementing this protocol is that we are implementing the energy, power and position of the node to choose the best energy route for sending data packets.

In figure 1 the block diagram is shown representative of zone based technology.

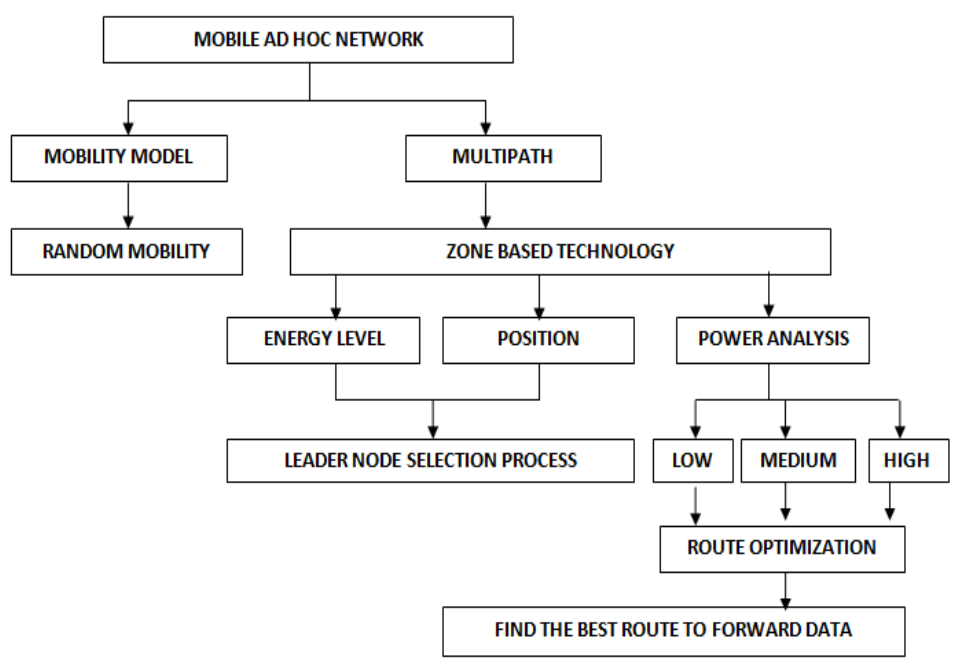

Fig.1. Block Diagram of the ZBLE

Our scenario is built under MANET, so it represents the MANIT network. Here the Random Mobility model has been taken, which allows the nodes to move randomly. Between the source and the destination, we get many paths from multipath technology. But in these ways, we have to choose some optimize path. The zonebased model is coming under multipath routing. There are three categories to work with this zone-based model, how to implement a zone-based model with the help of multiple paths, energy labels, position tracking, power analysis.

We will get a selection of the best path through which we will be able to achieve zone based technology. In this process, we will select the path based on the zone created by its members and leader node. Zone Leader Node and Members node are selected by keeping in mind two factors. Energy labeling and positioning tracking mean the distance.

Leader node can be selected only after the assumption of energy label and position tracing. After selecting the Leader node, the power analysis is classified into three labels, low, medium, and high.

Based on these three labels, it has been decided that which node should be appropriate to carry out the data? Here, the route has been adapted to the zone based technique with the help of many routing, energy label, position tracking and power analysis.

\section{Methodology}

Multipath routing in MANETs is difficult due to the constantly changing network topology and link capability. There are some properties in the nodes of MANETs which are as follows: The nodes are not stable 
and they dynamically change their place. Every node has the same capability in the duration of data processing, computational power, and data storage. Due to these properties, the energy of the node decreases which affects the efficiency of the network.

This applies a new multipath routing protocol, which is called Zone-based Leader Selection Energy Constrained AOMDV Routing Protocol (ZBLE) with a zone-based routing protocol, which is a combination of zone-based and leader selection functions.

Our approach is proposed, which is different from the existing methods. In this approach, the performance of the AOMDV protocol improves performance based on the selection of zone-based leader nodes. Now whenever a sender wants to send data, he uses several methods and every time he measures and stores the selection of residual energy and leader nodes. Here we reduce energy conservation and increase the percentage of receiving data in the network. In traditional AOMDV, RREQs use several paths. Energy is not kept in mind to choose these paths. Here the functioning of the proposed system with the help of Figures 2 is shown by the flow chart.

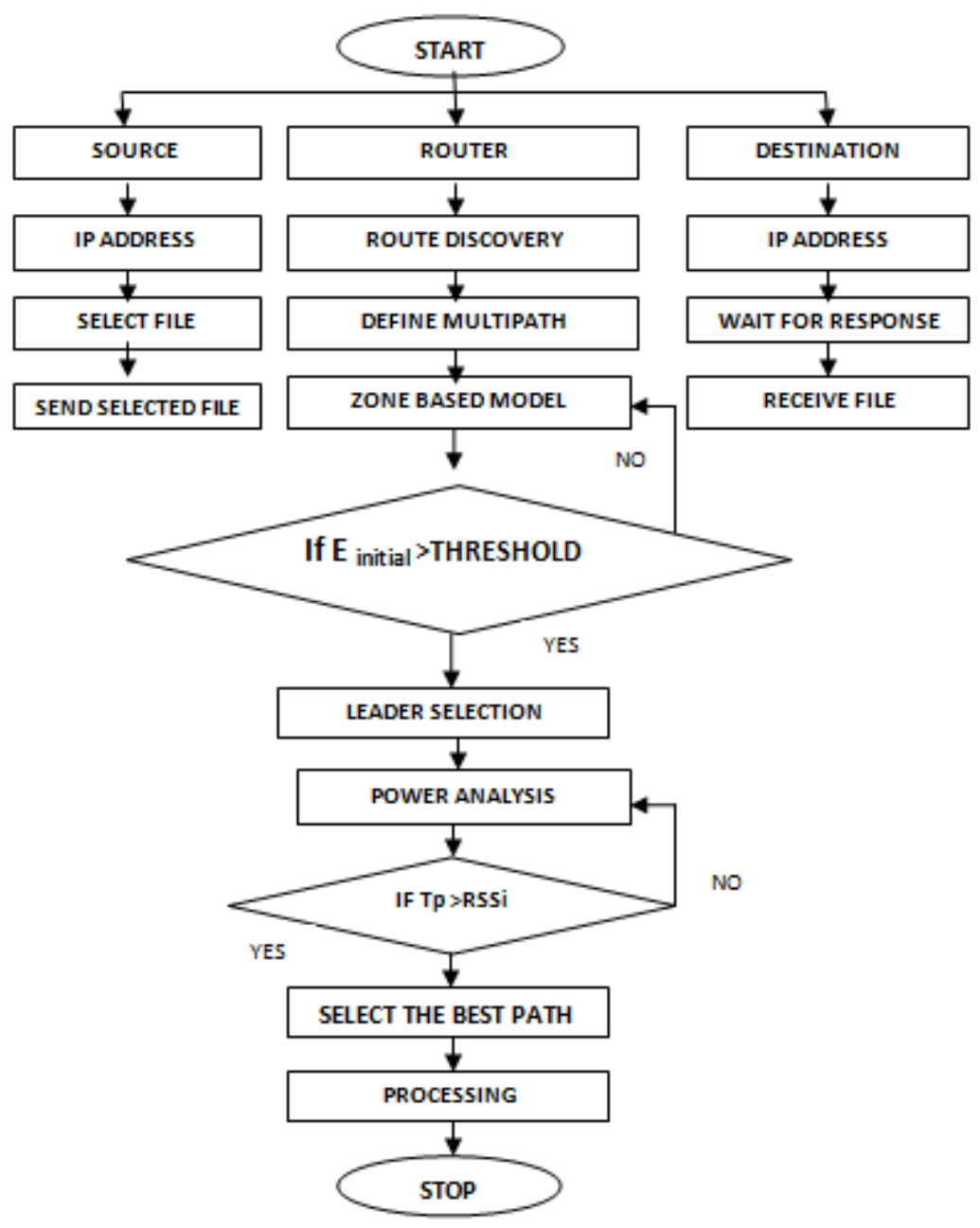

Fig.2. Flow Chart of the ZBLE 
In this figure 2, we have tried to understand this technique with the help of the flow diagram. This flow diagram presents the flow of the functions described in the above-mentioned block diagram. Mobile ad-hoc is implemented using the zone-based model here. Here is some energy in all the nodes. Based on the Threshold value in this model, it has been decided that any node is capable of making the transmission. All nodes have some battery labels but the initial battery labels that we can give. Therefore, each node has been labeled the initial battery, and this energy label gradually decreases. We cannot predict energy labels. Node transmission power is obtained on the basis of its energy strength.

If the energy is lower than the power threshold, it means that a special node is not capable of transmitting due to the low amount of energy node. And if the energy is greater than or equal to the power threshold, it means that the special node is able to transmit and communicate. If the node with a value greater than threshold value is found, then it should be selected as a leader node or else go back to the zone-based model. Now the power has been analyzed. Power analysis means transmission power and reception power. If the cost of transmission power is higher than RSS (Received Signal Strength), then the route should be chosen and processed, otherwise if it does not have any instrument then it returns power analysis.

\section{Proposed Algorithm}

The help of algorithm is showing Zone based technology in this section. Whenever we have to communicate in any network, we need to search for a source and destination. Therefore the source and destination have been initially initialized. The second stage is the mobility model. With the dynamic model, the position of the node is detected and we can easily find out the beginning and end position of all the nodes through this model. How many nodes are in every zone the selection of leader nodes and the information of neighboring nodes can also be obtained by this model, how many nodes in the range of their zones can help to forward the data. And we can also make that node a leader node. After selection of Leader node and Zone Members, it has been checked to represent the power signal. Leader node collects forward nodes by analyzing power analysis on the basis of transmission power and reception power. The forwarder selects the forwarder node using the max density, minimum dentistry and maximum packet size in the node selection method. Using the RSS value, selecting the forward node, the best path has been selected.

Every node should have these following characteristics:

Speed: Node velocity

Power signal: Signal strength of the node

Gap: Distance between the particular node and destination

Condition 1:

Speed: Slow Power signal: High Gap: small

Condition 2:

Speed: Medium Power signal: Medium Gap: Minimum

Condition 3:

Speed: High Power signal: Low Gap: Large

To solve the above stated problem the following steps are preformed: 


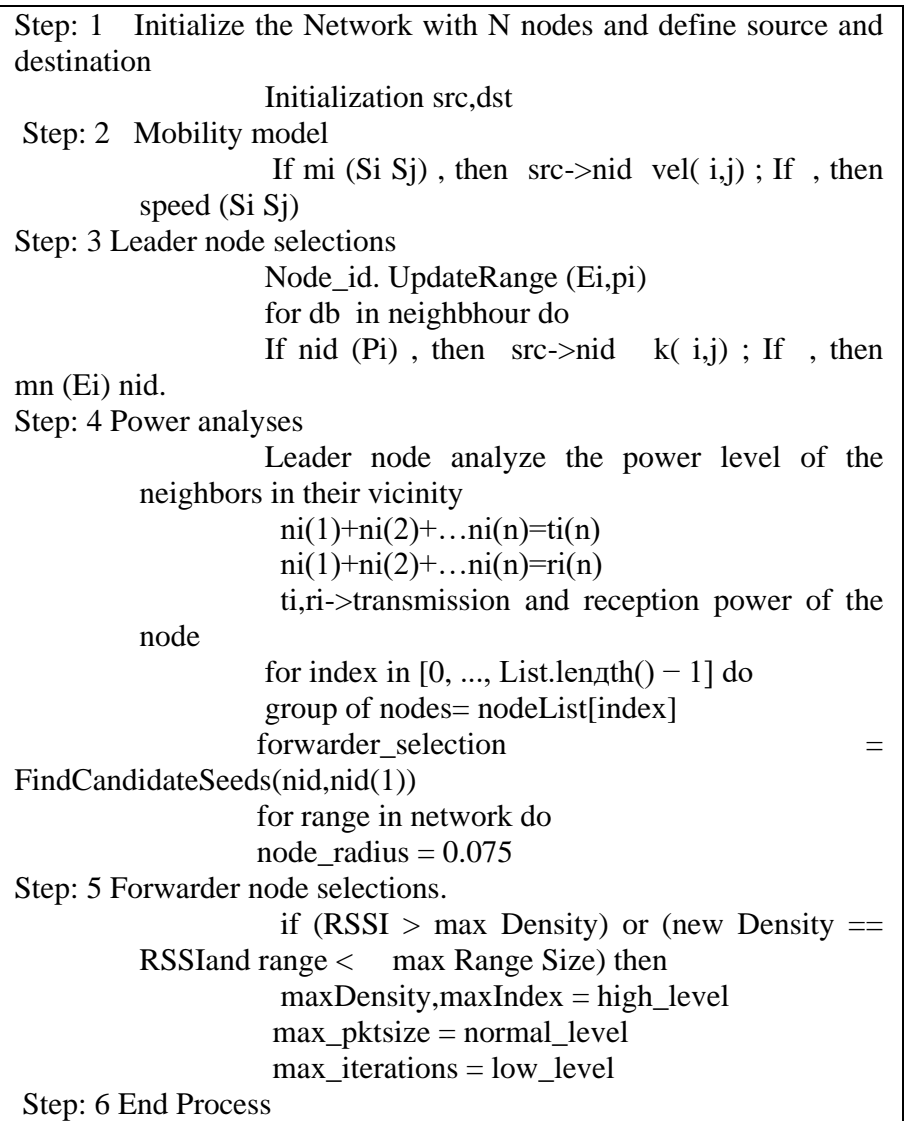

\section{Simulation Results}

\section{A. Simulation Scenarios}

Table 1. Various Simulation Scenarios

\begin{tabular}{|l|l|l|}
\hline Scenario Elements & Values & Unit \\
\hline Number of nodes & 100 & Nodes \\
\hline Node speed & $10,15,20,25,30$ & Meter/second \\
\hline Queue size & 50 & packets \\
\hline Simulation area & $1507 * 732$ & Meter2 \\
\hline Routing protocols & AODV, AOMDV, ZBLE & Protocol \\
\hline Mobility model & Random way point & \\
\hline Packet size & 512 & Bytes \\
\hline Traffic type power & CBR & \\
\hline Initial energy & 50 & Joules \\
\hline $\begin{array}{l}\text { Transmission } \\
\text { consumption }\end{array}$ & 0.035 & Joules \\
\hline $\begin{array}{l}\text { Receive } \\
\text { consumption }\end{array}$ & 0.100 & Joules \\
\hline Idle Power & 0.0175 & Joules \\
\hline Sense Power & 30 & Joules \\
\hline Simulation time & seconds \\
\hline
\end{tabular}


In this simulation model, we have used a Constant Bit Rate (CBR) as a traffic source with 100 mobile nodes, which are randomly presented in the 1507 meters * 732 meters network area. The initial energy level has been set for $50 \mathrm{JU}$. We have given the simulation time like 10, 15, 20, 25, 30 seconds. And the size of the node speed and packets is set to $3 \mathrm{~m} / \mathrm{s}$ and 512 bytes, respectively. The simulation time is set to 30 seconds.

\section{B. Performance Parameters}

To evaluate the performance of our proposed algorithm, different Performance metrics are considered here:

\section{1) Packet Delivery Ratio (PDR):}

This is the ratio of data packets, which were transported to the destination node, to the data packets generated by the source.

Figure 3 shows the graph of the packet Delivery ratio simulation time and the different simulations for ZBLE, AOMDV and AODV routing protocols reflect the variation of the packet Delivery ratio at the time. Simulation time is varied as $10,15,20,25$ and 30 seconds.

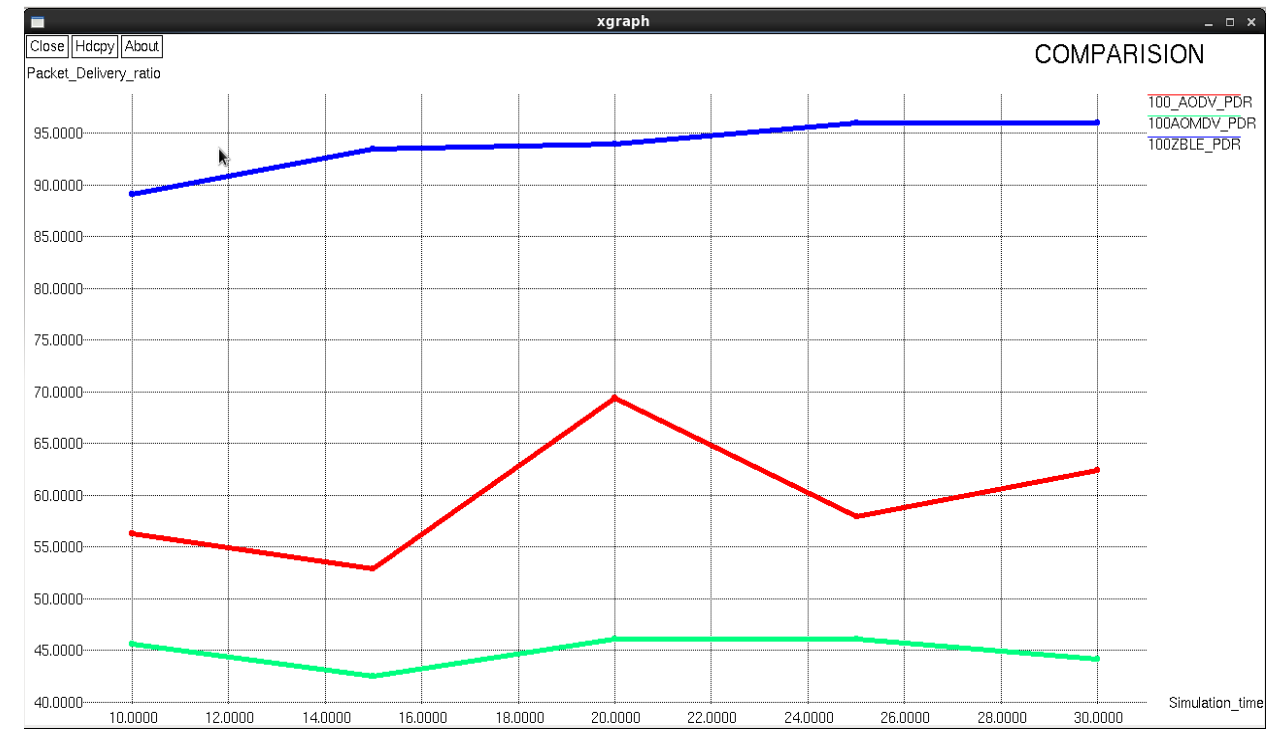

Fig.3. Graph of packet delivery ratio with simulation time

Despite the failure of any opportunity or route, ZBLE has a high PDR. These PDRs are high due to the availability of several paths. As the simulation time increases, the packet Delivery ratio also increases. Compared to both AODV and AOMDV protocol, ZBLE has a better performance in terms of packet delivery ratio.

\section{Throughput}

Throughput is known as the number of bits that the destination has successfully received.

In fig 4, the on-axis shows the simulation time and throughput on the Y-axis. With the help of this figure, we have shown the effect of throughput on different simulation times. The simulations are varied as May 10, 15, 20, 25 and 30 seconds. When the simulation time increases, the throughput is also increased. Better performance in the throughput of the ZBLE protocol than both AODV and AOMDV protocols. 


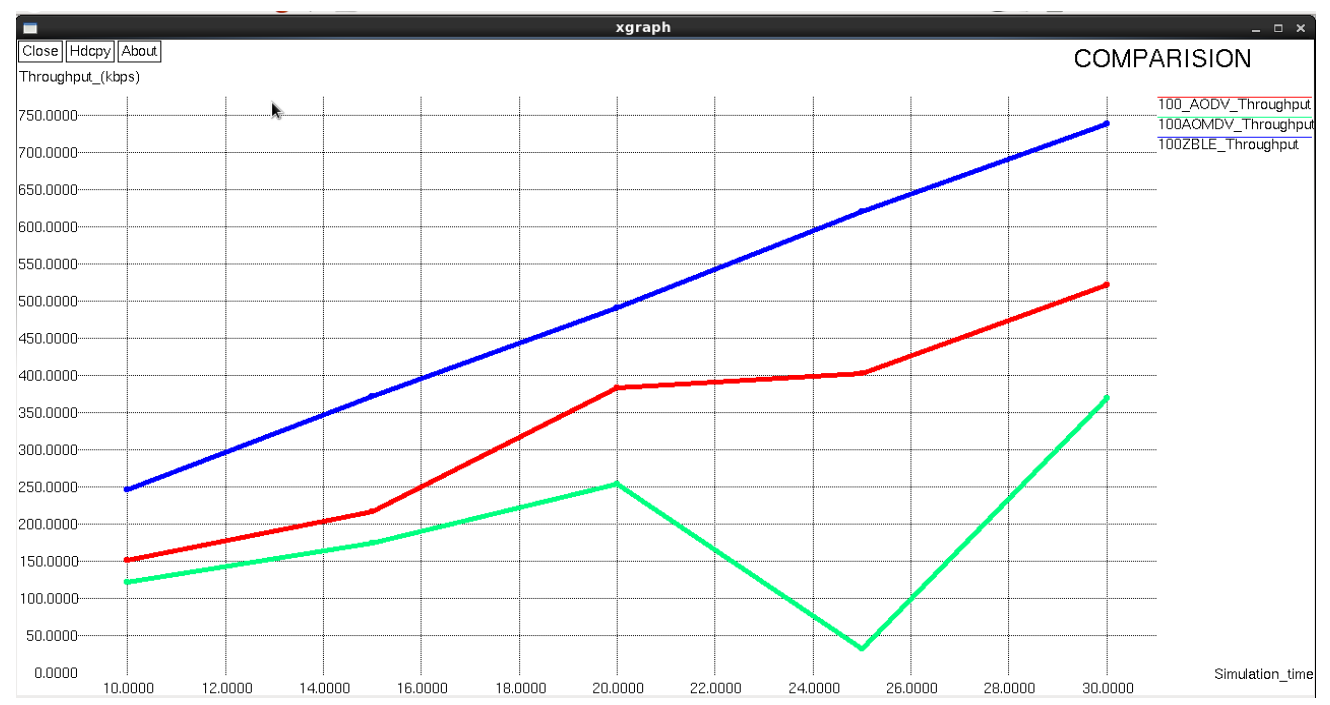

Fig.4. Graph of throughput with simulation time

\section{End-to-End delay}

The average time of successfully carrying end-to-end delay by the data packet is successfully transmitting messages from source to destination. This includes all types of delays, such as the packet queue in the interface queue; Time of promotion and transfer time; and buffering during the root discovery latency.

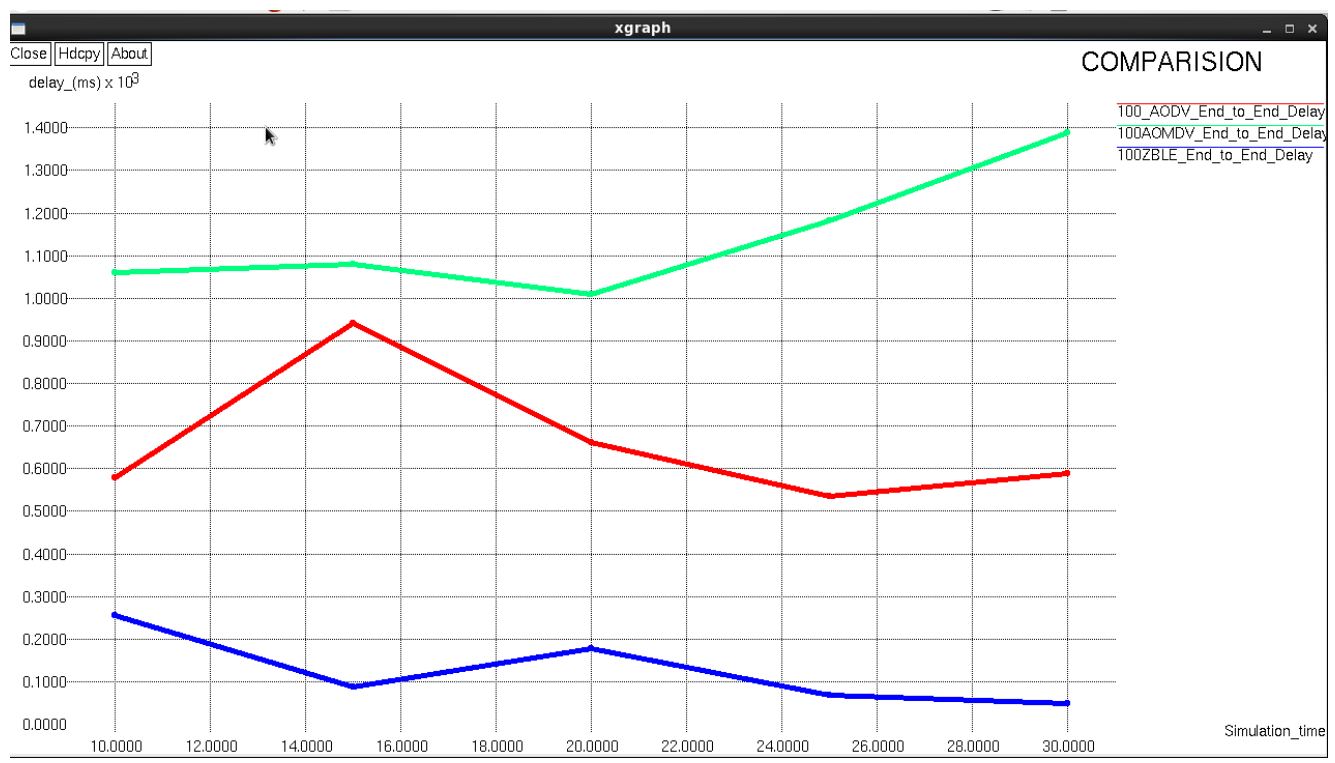

Fig.5. Graph of End to end delay with simulation time 
ZBLE (Zone-based Leader Elections Constructed AOMDV) tries to find an alternate route to the destination so that whenever a link breaks, the end-to-end delay of ZBLE is lower than AOVDV and AODV. Figure 5 shows the end-to-end delayed version and is showing better performance. The end-to-end delay in ZBLE is minimal because it is the most energy efficient way to avoid delays in packet transmission through multiple routes.

\section{Energy Consumption}

Energy consumption refers to the amount of energy spent by the network node during the simulation time. This level of the energy level of each node is achieved by factoring at the end of the simulation, the initial energy of each.

Fig.6 Comparison of Energy Consumption shows the graph. ZBLE Zone-based Topology, AODV, and AOMDV have shown variation in energy consumption. It rises in ZBLE because it is designed to choose from the highest energy levels and the source of the smallest energy level from the source.

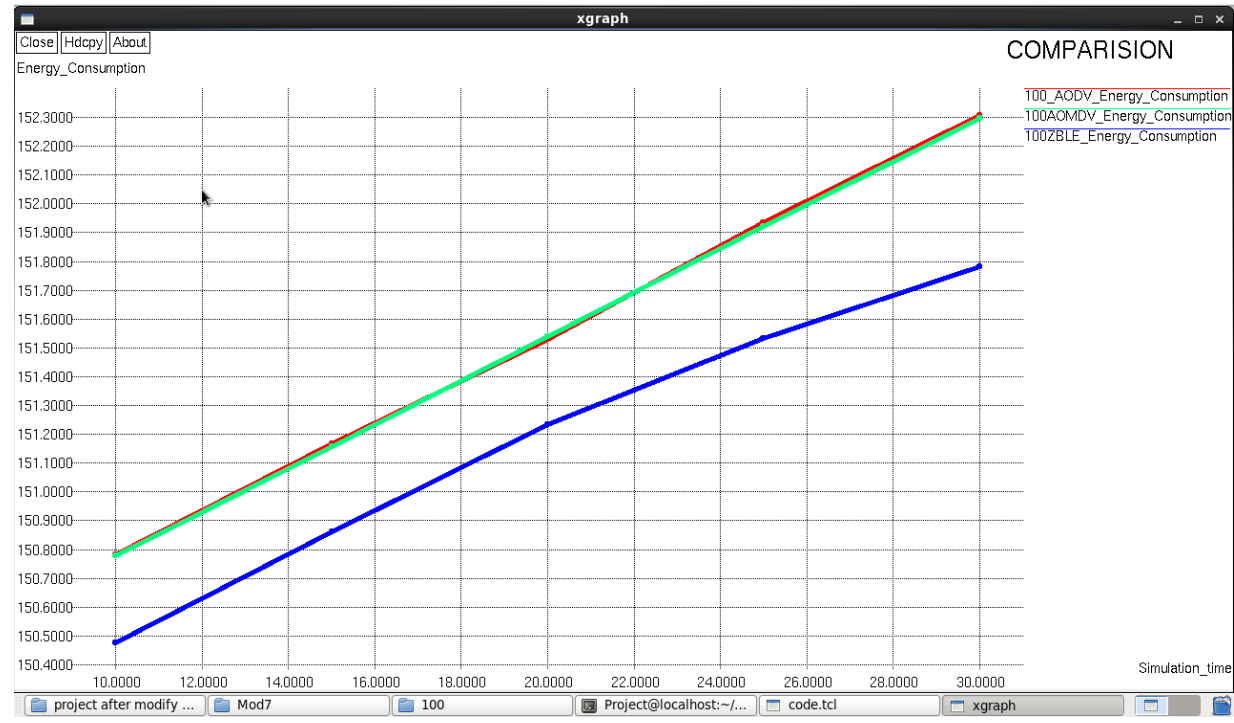

Fig.6. Graph of energy consumption with simulation time

ZBLE consume minimal energy because it contains information about most energy efficient paths. This sends the data packet to the highest energy and from the minimum source to the distance of the destination. In addition, it provides road transit facility in case of failure of any route.

\section{Network Lifetime}

Network lifetime refers to the time required to exhaust the battery of $\mathrm{N}$ mobile nodes.

Fig. 7 demonstrates the comparison of the lifetime of the simulation network. In this figure, the $\mathrm{x}$ axis shows the simulation time and when the $\mathrm{Y}$ axis timer changes time, then the number of nodes for the ZBLE, AODV and AOMDV indicates the exhaustion. ZBLE increases the life of its network as it routes traffic to high energy nodes in the network. In case, when the energy of these nodes is exhausted, topology has the property to gather information about various energy efficient routes and hence it transfers traffic on the shortest route for the next energy efficient, thus network Enhances life. 


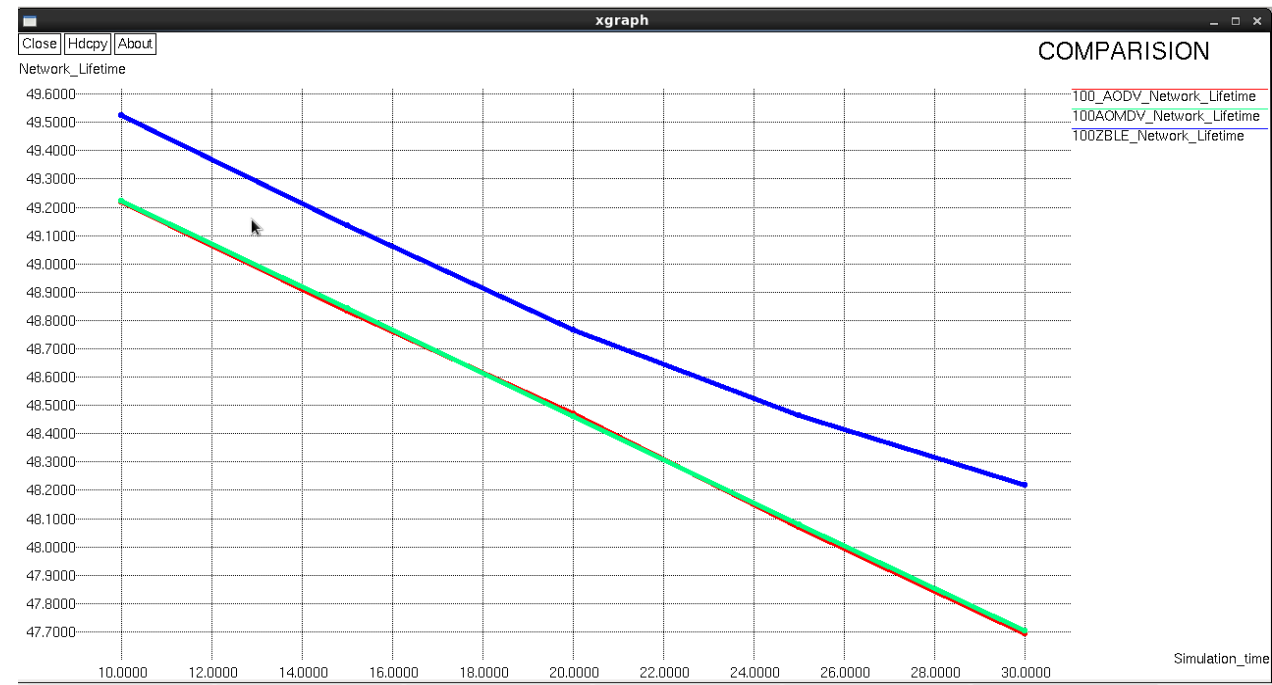

Fig.7. Graph of network lifetime with simulation time

Here we can compare performance enhancements by displaying all the enhancements in the form of tables. With the help of the following tables, we compare performance metrics on different simulation scenarios. By comparing the proposed algorithm with various existing protocols in this table, we found the ZBLE protocol best.

Table 2. Comparison of PDR

\begin{tabular}{|l|l|l|l|}
\hline \multirow{2}{*}{$\begin{array}{l}\text { Simulation } \\
\text { Time } \\
\text { Second }\end{array}$} & \multicolumn{3}{|c|}{ Packet delivery ratio (PDR) } \\
\cline { 2 - 4 } & AODV & AOMDV & ZBLE \\
\hline 10 & 56.3163 & 45.5414 & 89.0665 \\
\hline 15 & 52.8433 & 42.4411 & 93.5023 \\
\hline 20 & 69.413 & 46.0608 & 93.988 \\
\hline 25 & 57.9648 & 46.0278 & 96.0229 \\
\hline 30 & 62.4235 & 44.1706 & 95.9624 \\
\hline
\end{tabular}

Table 3. Comparison of Throughput

\begin{tabular}{|l|l|l|l|}
\hline \multirow{2}{*}{$\begin{array}{l}\text { Simulation } \\
\text { Time } \\
\text { Second }\end{array}$} & \multicolumn{3}{|c|}{ Throughput } \\
\cline { 2 - 4 } & AODV & AOMDV & ZBLE \\
\hline 10 & 10150.52 & 10121.72 & 10245.00 \\
\hline 15 & 15216.20 & 15173.64 & 15371.55 \\
\hline 20 & 20382.47 & 20253.80 & 20490.15 \\
\hline 25 & 25401.62 & 25318.92 & 25619.96 \\
\hline 30 & 30521.08 & 30368.71 & 30738.42 \\
\hline
\end{tabular}


Table 4. Comparison of End To End Delay

\begin{tabular}{|l|l|l|l|}
\hline \multirow{2}{*}{$\begin{array}{l}\text { Simulation } \\
\text { Time } \\
\text { Second }\end{array}$} & \multicolumn{3}{|c|}{ End To End Delay } \\
\cline { 2 - 4 } & AODV & AOMDV & ZBLE \\
\hline 10 & 579.79 & 1061.11 & 256.695 \\
\hline 15 & 940.768 & 1079.9 & 87.9443 \\
\hline 20 & 662.81 & 1008.82 & 177.819 \\
\hline 25 & 535.12 & 1182.67 & 68.5571 \\
\hline 30 & 588.861 & 1389.71 & 47.868 \\
\hline
\end{tabular}

Table 5. Comparison of Energy Consumption

\begin{tabular}{|l|l|l|l|}
\hline \multirow{2}{*}{$\begin{array}{l}\text { Simulation } \\
\text { Time } \\
\text { Second }\end{array}$} & \multicolumn{3}{|c|}{ Total energy consumption } \\
\cline { 2 - 4 } & AODV & AOMDV & ZBLE \\
\hline 10 & 150.781 & 150.778 & 150.475 \\
\hline 15 & 151.168 & 151.157 & 150.863 \\
\hline 20 & 151.529 & 151.539 & 151.233 \\
\hline 25 & 151.933 & 151.921 & 151.534 \\
\hline 30 & 152.308 & 152.297 & 151.781 \\
\hline
\end{tabular}

Table 6. Comparison of Network lifetime

\begin{tabular}{|l|l|l|l|}
\hline \multirow{2}{*}{$\begin{array}{l}\text { Simulation } \\
\text { Time } \\
\text { Second }\end{array}$} & \multicolumn{3}{|c|}{ Network lifetime } \\
\cline { 2 - 4 } & AODV & AOMDV & ZBLE \\
\hline 10 & 49.2187 & 49.2223 & 49.5255 \\
\hline 15 & 48.8319 & 48.843 & 49.137 \\
\hline 20 & 48.4706 & 48.4612 & 48.767 \\
\hline 25 & 48.0674 & 48.0788 & 48.4656 \\
\hline 30 & 47.6918 & 47.7026 & 48.2193 \\
\hline
\end{tabular}

\section{Conclusions}

In this research, we propose ZBLE (Zone Based Leader Selection Energy Constrained AOMDV Routing Protocol), a protocol based on Zone Technology, which has been simulated using various simulation times using NS-2.35. These scenarios are tested by 5 performance matrix packet delivery ratios, throughput, end-toend-delay, energy consumption and network lifetime. The results of simulations have proved that the proposed ZBLE protocol has delivered better results than modern two protocols AODV and AOMDV. This is an amazing activity to help ZBLE's help to maximize the life of the network. 


\section{References}

[1] IETF MANET WG (Mobile ad hoc network), http://www.ieft.ora/html.charters/manet-charter.html.

[2] M. Bheemalingaiah, M. M. Naidu, D. Sreenivasa Rao, et al., "Energy Aware Node-Disjoint Routing in Mobile Ad Hoc Networks," Journal of Theoretical and Applied Information Technology, Vol. 5, No. 4, pp 416- 431, 2009.

[3] Vaibhav, "Mobility Models and traffic Pattern Generation Based Optimization of Reactive Protocols", International Journal Intelligence Engineering Informatics, 2012.

[4] D. G. S. Mueller, "Multipath routing in mobile ad hoc networks: issues and challenges," Performance Tools and Application to Networked Systems, ser. Lecture Notes in Computer Science, M. C. Calzarossa and E. Gelenbe, Eds., vol. 2965, pp.209-234, Apr 2004.

[5] Lalar, Sachin, and A. Yadav. "Comparative Study of Routing Protocols in MANET." OJCST 10 (2017): 174.

[6] VarunSingla and Nailja Wadhwa, "Comparative Performance Analysis of DSDV, AOMDV and ZRP Routing Protocols in VANET using NS2", International Journal of Computer Science and Information Technologies, Vol. 5 (2), PP. 2238-2241, Year 2014.

[7] Ghassan Samara, Wafaa A.H. Al-Salihy and R. Sures, "Security Analysis of Vehicular Ad Hoc Networks (VANET)", Second International Conference on Network Applications, Protocols and Services, PP. 55 60 , Year 2010.

[8] Ali, S.A.V, Salem Jeyaseelan,,Hariharan S, "Enhanced Route Discovery in Mobile Ad hoc Networks", Computing Communication \& Networking Technologies (ICCCNT-IEEE), PP. 1-5, 26th_28th July 2012, Coimbatore, India.

[9] VirendraDani and Vijay Birchha, "Security Enhancement Technique for Defending Wormhole Attacks in Wireless Mesh Networks", (IJCSIT) International Journal of Computer Science and Information Technologies, Vol. 6 (4), PP. 3943-3948, 2015.

[10] Ehsan, Z. Uzmi, "Performance comparison of adhoc wireless network routing protocols", Proceedings of IEEE International Multi-topic Conference (INMIC) 2004

[11] Mahesh K. Marina and Samir R. Das,"On-Demand Multipath Distance Vector Routing in Ad Hoc Networks" in IEEE Proceedings 2001.

[12] M.K. Marina, S.R. Das, "On-demand Multipath Distance Vector Routing in Ad Hoc Networks," in Proceedings of the International Conference for Network Procotols, 2001.

[13] Basu Dev Shivahare, CharuWahi, and Shalini Shivhare, "Comparison Of Proactive And Reactive Routing Protocols In Mobile Ad-hoc Network Using Routing Protocol Property", International Journal of Emerging Technology and Advanced Engineering(IJETAE), Volume 2, PP. 356- 359, March 2012.

[14] Ali, S.A.V, Salem Jeyaseelan,,Hariharan S, "Enhanced Route Discovery in Mobile Ad hoc Networks", Computing Communication \& Networking Technologies (ICCCNT-IEEE), PP. 1-5, 26th_28th July 2012, Coimbatore, India

[15] Soundararajan S, R.S. Bhuvaneswaran "Adaptive Multi-Path Rout- ing for Load Balancing in Mobile Ad Hoc Networks" Journal of Computer Science, vol. 8 Issue (5), ISSN 1549-3636, pp. 648-655, 2012.

[16] Amjad Ali, Wang Huiqiang "Node Centric Load Balancing Routing Protocol for Mobile Ad Hoc Networks “, Proceeding of Internationl MultiConference of Enginners Computer Scientists 2012 Vol I, March 2012 ,Hong Kong.

[17] Tuan Anh Le, Choong Seon Hong, Member, IEEE, Md. Abdur Raz- zaque et. al. "An Energy-Aware Congestion Control Algorithm for Multipath TCP” IEEE Communications Letters, Vol. 16, No. 2, February 2012.

[18] Shalini Puri and Dr. Satish.R.Devene, "Congestion Avoidance and Load Balancing in AODV-Multipath using Queue Length", IEEE Se- cond International Conference on Emerging Trends in Engineering and Technology (ICETET), pp. 1138-1142, 2009. 
[19] Sneha R.Deshmukh, Vijay T.Raisinghani "EALBM: Energy Aware Load Balancing Multipath Routing Protocol for MANETs" IEEE Eleventh International Conference on Wireless and Optical Communications Networks (WOCN), pp. 1-7, 2014

[20] S.Venkatasubramanian, N.P.Gopalan, "A quality of service architecture for resource provisioning and rate control in mobile ad hoc network", International Journal of Ad hoc, Sensor \& Ubiquitous Computing (IJASUC), Vol. 1, No. 3, September 2010.

[21] Maheshwari, G., Gour, M., \& Mishra, S. K. (2014). Load Balancing Congestion Control Scheme to Improve the Capability of AOMDV Protocol in MANET.International Journal of Advanced Research in Computer Science and Electronics Engineering (IJARCSEE), 3(10), pp- 428.

\section{Authors' Profiles}

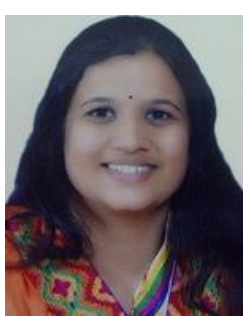

Rani Sahu received MCA. Degree (Hons) from Rajiv Gandhi Technical University, Bhopal in 2009. She is pursuing Ph.D.degree in computer applications from MANIT, Bhopal. Her research interests include Routing Protocol, Mobile Ad-Hoc Network.

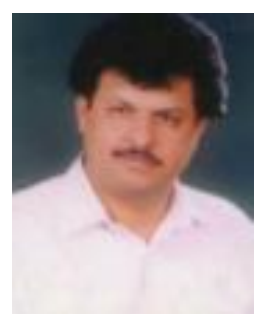

Sanjay Sharma, completed his Ph.D from Barkatullah University Bhopal in 2004, in the area of compressing large databases. He did his MCA from MANIT, Bhopal in 1990. He is also an IPv6 Certified Gold and Silver Network Engineer from IPv6 forum, University Sains Malaysia. He is having a teaching experience of 22 years, and currently he is Professor and Head of Department in MANIT Bhopal. His research interests include wireless networks, nextgeneration networks, Sensor Networks, 6LoWPAN, and Large Databases.

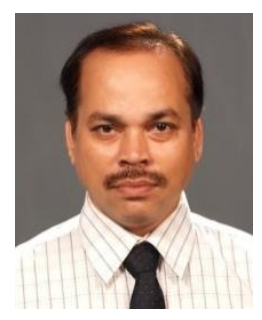

Dr. M.A. Rizvi is an Associate Professor of Computer Engineering \& Applications in National Institute of Techanical Teachers'Training \& Research, Bhopal, Madhya Pradesh, India. He obtained his PhD degree from MANIT Bhopal. His research interest is in the field of Network, Image processing, Data security, Data mining, E-learning, Cloud computing, Neural, Machine learning, Intelligent tutoring system amd more. He is having strong Interntional connections and contribution in research events. $\mathrm{He}$ has published approximately (40) International Journals \& conferences papers.

How to cite this paper: Rani Sahu, Sanjay Sharma, M.A. Rizvi, "ZBLE: Zone based Leader Selection Energy Constrained AOMDV Routing Protocol", International Journal of Wireless and Microwave Technologies(IJWMT), Vol.9, No.5, pp. 56-68, 2019.DOI: 10.5815/ijwmt.2019.05.05 